\title{
Occurrence of root caries in relation to specific dental health habits (oral hygiene practice) in adult population (30 - 70) years in Mosul city, Iraq
}

\author{
Ghada Dh AL-SAYAGI*
}

\begin{abstract}
This study was designed to evaluate the relationship between the occurrence of root surface caries (RSC) and a subject's dental health habits such as the frequency of tooth brushing and the use of other cleaning aids such as chewing stick and the dental floss in the adult population aged $(30-70)$ years in Mosul city.

A sample of (1270) subjects [ $719(56.6 \%)$ males and 551 (43.4\%) females ] were collected randomly from different eight factories, seven primary schools, eight secondary schools and five colleges from Mosul University.

According to age, the sample was divided into four age groups $(30-39,40-$ $49,50-59$ and $60-69$ years).

The results of the study revealed that subjects with RSC in the young age group (30 - 39 years) claimed to brush their teeth once a day and twice a day or more, whereas subjects with RSC in the old age group (60 - 69 years) claimed to brush their tecth infrequently. Statistically, the differences between subjects with and without RSC were significant for all age groups. The study showed that generally subjects with and without RSC who claimed never use other cleaning aids reported higher percentage than those who used other cleaning aids. Indeed, those who claimed to use chewing stick displayed high rate than those who use dental floss.

It was concluded that dental health behavior influences root caries occurrence and that caries on root surface is associated with poor dental health habits.
\end{abstract}

Key Worls: Root caries, dental health, tooth brushing, chewing stick.

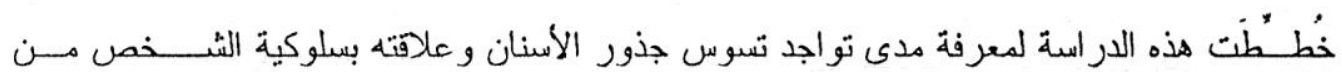

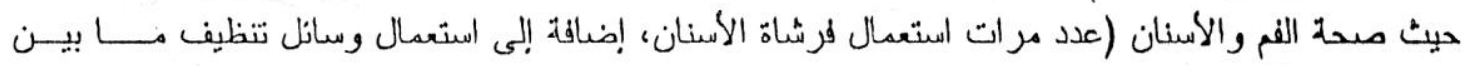

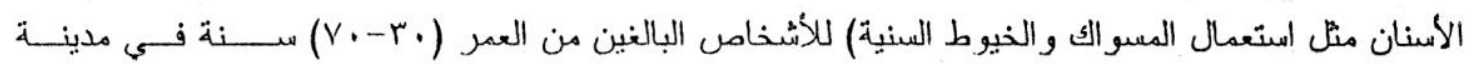

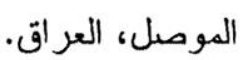

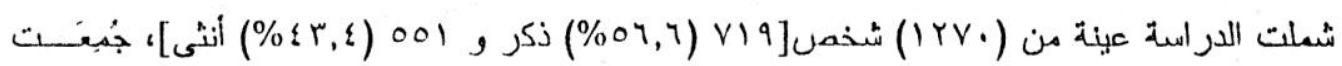

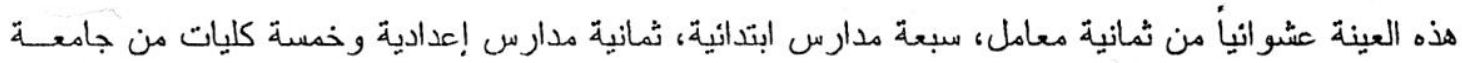

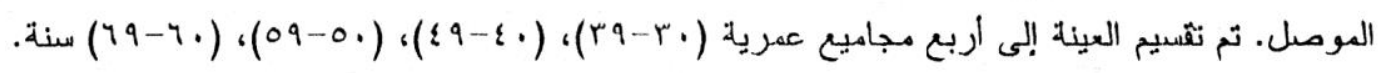

*Ghada Dhiaa AL-SAYAGH; BDS, MSc: Assistant Lecturer. Department of Pedodontics, Orthodontics, and Preventive Dentistry, College of Dentistry, University of Mosul, Mosul, IRAQ. 


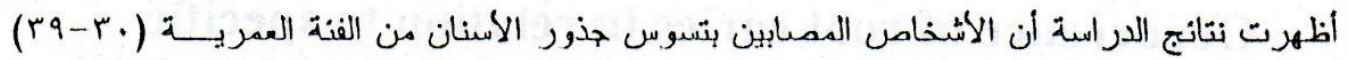

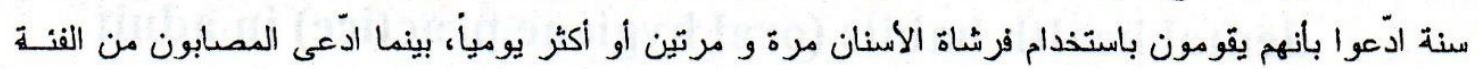

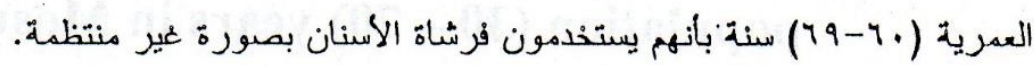

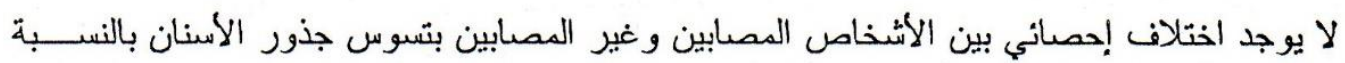

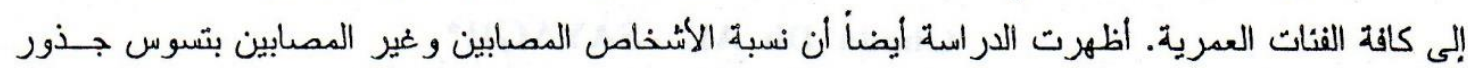

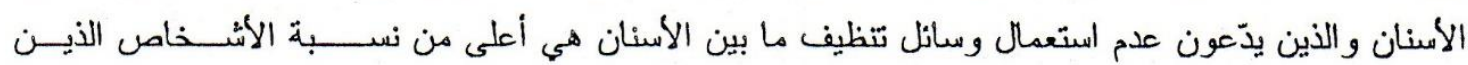

$$
\begin{aligned}
& \text { يستعملون هذه الوسائل. }
\end{aligned}
$$

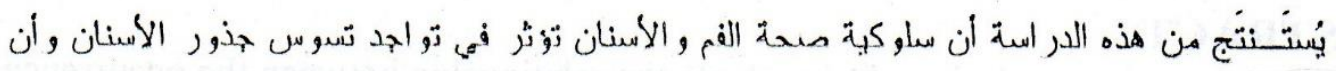

$$
\begin{aligned}
& \text { تسوس جذور الأسنان متو افق مع عادات صدة الفم والأسنان السيئة. }
\end{aligned}
$$

\section{INTRODUCTION}

Caries in modern man is typically regarded as a disease affecting the exposed crowns and as manifesting itself during childhood and adolescence ${ }^{(1)}$. In historical terms, however, this pattern of caries is comparatively recent and associated with westernised diets. In contrast, ancient skulls ${ }^{(2,3)}$ and primitive communities of the prescnt study ${ }^{(4,5)}$, typically show a predominance of root surface caries occurring at the amelocemental junction during adult life; coronal caries being relatively uncommon.

Root surface caries is also of frequent occurrence in western industrial countries but until recently little attention has been paid to it, presumably because of the much more severe problems posed by coronal caries and of its tendency to occur at an age when tooth loss has been accepted as the norm ${ }^{(1)}$.

The proportional increase in the elderly now being experienced in many of these countries, together with changes in the pattern of dental treatment to favor conservation rather than extraction. This means that in the future progressively more teeth will be retained to a greater age ${ }^{(6-10)}$, and hence root surface caries can be anticipated to show an increasing prevalence.

Dentists usually instruct their patients to perform daily oral hygiene procedures, avoid frequent sugar consumption, and visit a dentist regularly in order to prevent dental caries ${ }^{(11)}$.

Nyvad and Fejerskov ${ }^{(12)}$ have shown how active root caries lesions converted into inactive caries as a response to a subject's intensive oral hygiene procedure. Clinical studies including a frequent professional prophylaxis have reported that this could explain the decline of root caries occurrence in a high-risk population ${ }^{(13)}$ and prevent caries progression in adults ${ }^{(14)}$.

So, the purpose of this study was to investigate the relationship between the occurrence of RSC and the use of specific dental health habits like tooth brushing and the use of other cleaning aids such as chewing stick and dental floss in adult population ( $30-70$ years) in Mosul city. 


\section{MATERIALS AND METIIODS}

A random sample of (1270) subjects were collected with an age range from (30 - 70) years, taken from the city of Mosul from a random eight different factories, eight secondary schools, seven primary schools and five colleges from the University of Mosul.

The examination of the root surface caries (RSC) was carried out using plan mouth mirror and sickle - shaped explorer. All subjects were examined while seated in a side chair. The examination was carried out in a suitable room under natural daylight. used: -

The criteria described by Banting et al. ${ }^{(15)}$ for the identification of RSC were

1) A discrete well - defined and discoloured soft area.

2) An explorer enters easily and displays some resistance.

3) The lesion is located either in the cementoenamel junction or wholly on the root surface.

The questionnaire forms were completed by the dentist. The questions include general information like name, age and sex. All subjects were asked whether they used toothbrush or not. Those who answered "yes" were asked about the frequency of tooth brushing. Also, they asked about the use of other cleaning aids such as chewing stick and dental floss.

\section{Statistical Analysis:}

A statistical analysis of the data was conducted. The analysis in this study included the followings: -

1) Calculation of statistical parameters: The mean and percentage.

2) Analysis of the data by using t-test to determine the significant differences between the number of subjects affected by RSC and different variables like age, gender and dental health behaviors (like frequency of tooth brushing and use of other cleaning aids).

3) The chi-square test $\left(\chi^{2}\right)$ was used to determine the statistical significance among groups between the number of subjects affected with RSC and different variables such as age and use of other cleaning aids (like dental floss and chewing stick).

The differences were considered significant when the probability $(p)$ level equal to, or less than, $0.05(p<0.05)$; and when the probability $(p)$ was more than 0.05 it was regarded as insignificant.

\section{RESULTS}

The distribution of the sample by age and gender is shown in table (1). The sample consists of (1270) subjects [ $719(56.6 \%)$ males and $551(43.4 \%)$ females ]. The sample is divided into four age groups; namely, $(30-39),(40-49),(50-59)$ and $(60-69)$ years. 
Table (1): Distribution of the study sample according to age and gender

\begin{tabular}{|c|c|c|c|c|c|c|}
\hline \multirow{2}{*}{ 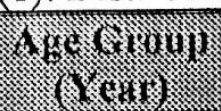 } & \multicolumn{2}{|c|}{ Mold } & \multicolumn{2}{|c|}{ Thunule } & \multicolumn{2}{|c|}{$160 \mathrm{~m}$} \\
\hline & Yrow & - & 10 & 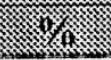 & 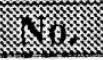 & 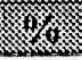 \\
\hline $30 \times 10,9=$ & 141 & 36.43 & 246 & 63.57 & 387 & 100 \\
\hline $40=1$. & 233 & 53.56 & 202 & 40.44 & 435 & 100 \\
\hline $50 \%$ & 245 & 72.70 & 92 & 27.30 & 337 & 100 \\
\hline $60 \quad 69$ & 100 & 90.09 & 11 & 9.91 & 111 & 100 \\
\hline T/vili & 719 & 56.61 & 551 & 43.39 & 1270 & 100 \\
\hline
\end{tabular}

Table (2: $a$ and b) illustrated the relationship between subjects with and without RSC and the frequency of tooth brushing according to the age groups and gender. The results of this study displayed that subjects with RSC who never do tooth brushing showed its higher percentage $(18.8 \%)$ in the age group $(50-59)$ years, while those subjects who claimed brushing their teeth infrequently showed its higher percentage $(92.2 \%)$ in the old age group $(60-69)$ years. In contrast, those subjects with RSC who claimed brushing their tecth once daily and more reported its higher percentage $(66.0 \%)$ in the age group $(30-39)$ years. The differences between total subjects with and without RSC for all agc groups were statistically significant.

Table (3) showed that, out of the total sample, subjects with RSC who never using any cleaning aids reported their higher percentage $(71.2 \%)$ in the old age group $(60-69)$ years. In the same manner, those who use chewing stick and dental floss registered their higher percentages $(17.1 \%$ and $4.5 \%)$, respectively in the old age group $(60-69)$ years.

Table (2a): A comparison between subjects with and without RSC

and the frequency of tooth brushing according to the age aind gender

\begin{tabular}{|c|c|c|c|c|c|c|c|c|c|c|c|c|c|}
\hline \multirow[b]{3}{*}{ 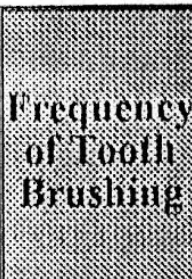 } & \multirow[b]{3}{*}{ (1) } & \multicolumn{6}{|c|}{ W. } & \multicolumn{6}{|c|}{ 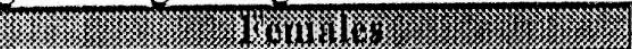 } \\
\hline & & \multicolumn{3}{|c|}{ 1VII 15 - } & \multicolumn{3}{|c|}{ 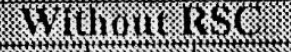 } & \multicolumn{3}{|c|}{ 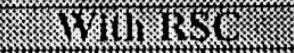 } & \multicolumn{3}{|c|}{ 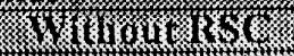 } \\
\hline & & 8 & $\frac{y}{2}$ & (x) & 的 & hin & 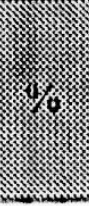 & 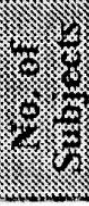 & 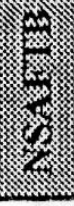 & 纱 & on & . & \\
\hline \multirow{5}{*}{. } & 30.39 & 52 & 6 & 11.5 & 89 & 3 & 3.4 & 95 & 2 & 2.1 & 151 & 1 & 0.7 \\
\hline & $\left(1 / x^{\prime}\right)$ & 99 & 10 & 10.1 & 134 & 9 & 6.7 & 68 & 10 & 14.7 & 134 & 2 & 1.5 \\
\hline & 50.69 & 126 & 20 & 15.9 & 119 & 16 & 13.4 & 34 & 10 & 29.4 & 58 & 3 & 5.2 \\
\hline & 6160 & 95 & 0 & 0.0 & 5 & 0 & 0.0 & 8 & 4 & 50.0 & 3 & 0 & 0.0 \\
\hline & Trokn) & 372 & 36 & 9.7 & 347 & 28 & 8.1 & 205 & 26 & 12.7 & 346 & 6 & 1.7 \\
\hline \multirow{5}{*}{ } & 30,42 & 52 & 19 & 36.5 & 89 & 30 & 33.7 & 95 & 23 & 24.2 & 151 & 18 & 11.9 \\
\hline & $40=19$ & 99 & 63 & 63.6 & 134 & 40 & 29.9 & 68 & 23 & 33.8 & 134 & 12 & 8.9 \\
\hline & 50 & 126 & 59 & 46.8 & 119 & 30 & 25.2 & 34 & 16 & 47.1 & 58 & 31 & 53.4 \\
\hline & 60.69 & 95 & 91 & $\overline{95.8}$ & 5 & 3 & 60.0 & 8 & 4 & 50.0 & 3 & 2 & 66.7 \\
\hline & Y 101 & 372 & 295 & 79.3 & 347 & 103 & 29.7 & 205 & 66 & 32.2 & 346 & 63 & 18.2 \\
\hline \multirow{5}{*}{ 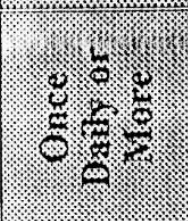 } & 30.39 & 52 & 27 & 51.9 & 89 & 56 & 62.9 & 95 & 70 & 73.7 & 151 & 132 & 87.4 \\
\hline & $10 \times 49$ & 99 & 26 & 26.3 & 134 & 85 & 63.4 & 68 & 35 & 51.5 & 134 & 120 & 89.0 \\
\hline & 50 . & 126 & 47 & 37.3 & 119 & 73 & 61.3 & 34 & 8 & 23.5 & 58 & 24 & 41.4 \\
\hline & 6060 & 95 & 4 & 4.2 & 5 & 2 & 40.0 & 8 & 0 & 0.0 & 3 & 1 & 33.3 \\
\hline & Toul & 372 & 104 & 28.0 & 347 & 216 & 62.2 & 205 & 113 & 55.1 & 346 & 277 & 80.1 \\
\hline & & & & & & & & & & & & & \\
\hline
\end{tabular}


Table (2b): A comparison between total subjects with and without RSC and the frequency of tooth brushing according to the age group

\begin{tabular}{|c|c|c|c|c|c|c|c|}
\hline \multirow[b]{3}{*}{ 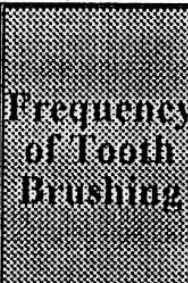 } & \multirow[b]{3}{*}{ 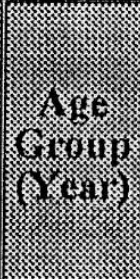 } & \multicolumn{6}{|c|}{ 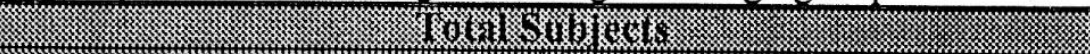 } \\
\hline & & \multicolumn{3}{|c|}{ 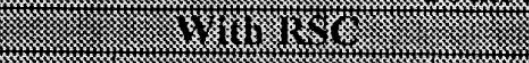 } & \multicolumn{3}{|c|}{ 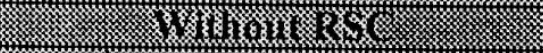 } \\
\hline & & r. & 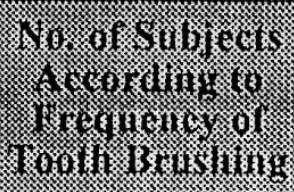 & 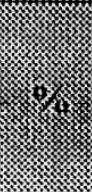 & … & 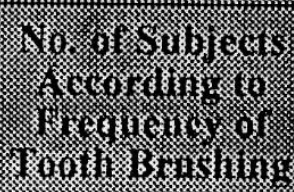 & 筙 \\
\hline \multirow{5}{*}{ 站 } & 30. 36 & 147 & 8 & 5.4 & 240 & 4 & 1.7 \\
\hline & ma & 167 & 20 & 12.0 & 268 & 11 & 4.1 \\
\hline & 60. & 160 & 30 & 18.8 & 177 & 19 & 10.7 \\
\hline & $606 \%$ & 103 & 4 & 3.9 & 8 & 0 & 0.0 \\
\hline & W. & 577 & 62 & 10.7 & 693 & 34 & 4.9 \\
\hline \multirow{5}{*}{, } & 30.29 & 147 & 42 & $\overline{28.6}$ & 240 & 48 & 20.0 \\
\hline & 10049 & 167 & 86 & 51.5 & 268 & 52 & 19.4 \\
\hline & 50 & 160 & 75 & 46.9 & 177 & 61 & 34.5 \\
\hline & 60 & 103 & 95 & 92.2 & 8 & 5 & 62.5 \\
\hline & Trul & 577 & 298 & 51.6 & 693 & 166 & 24.0 \\
\hline \multirow{5}{*}{ 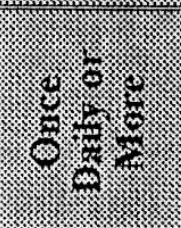 } & 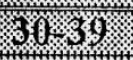 & 147 & 97 & 66.0 & 240 & 188 & 78.3 \\
\hline & 16. & 167 & 61 & 36.5 & 268 & 205 & 76.5 \\
\hline & 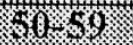 & 160 & 55 & 34.4 & 177 & 97 & 548 \\
\hline & $60.6 \%$ & 103 & 4 & 3.9 & 8 & 3 & 37.5 \\
\hline & Whar & 577 & 217 & 37.6 & 693 & 493 & 71.1 \\
\hline
\end{tabular}

Table (3): Subjects with and without RSC and the use of cleaning aids according to age group and gender

\begin{tabular}{|c|c|c|c|c|c|c|c|c|c|c|c|c|c|}
\hline \multirow{3}{*}{ 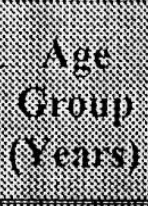 } & \multirow{3}{*}{ ming } & \multicolumn{4}{|c|}{ - 114L } & \multicolumn{4}{|c|}{ 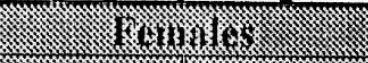 } & \multicolumn{4}{|c|}{ mak } \\
\hline & & \multicolumn{2}{|c|}{ (1) } & \multicolumn{2}{|c|}{ I. 1010} & \multicolumn{2}{|c|}{ - } & \multicolumn{2}{|c|}{ 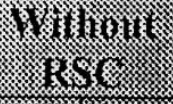 } & \multicolumn{2}{|c|}{-1. } & \multicolumn{2}{|c|}{ 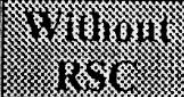 } \\
\hline & & 聮 & 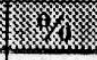 & 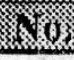 & 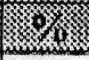 & sing & 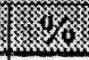 & Max & . & 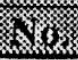 & 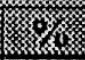 & 㬎㱍 & 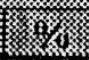 \\
\hline \multirow{3}{*}{80} & 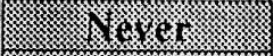 & 56 & 62.9 & 32 & 61.5 & 131 & 86.8 & 88 & 92.6 & 120 & 31.0 & 187 & 48.3 \\
\hline & / & 25 & 28.1 & 19 & 36.5 & 7 & 4.6 & 3 & 3.2 & 22 & 5.7 & 32 & 8.3 \\
\hline & 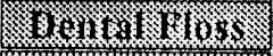 & 8 & 9.0 & 1 & 1.9 & 13 & 8.6 & 4 & 4.2 & 5 & 1.3 & 21 & 5.4 \\
\hline \multirow{3}{*}{10.949} & a & 95 & 70.9 & 75 & 75.8 & 116 & 86.6 & 61 & 89.7 & 136 & 31.3 & 211 & 48.5 \\
\hline & M. & 38 & 28.4 & 23 & 23.2 & 11 & 8.2 & 6 & 8.8 & 29 & 6.7 & 49 & 11.3 \\
\hline & 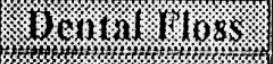 & 1 & 0.7 & 1 & 1.0 & 7 & 5.2 & 1 & 1.5 & 2 & 0.5 & 8 & 1.8 \\
\hline \multirow{3}{*}{60.} & x. & 93 & 78.2 & 117 & 92.9 & 57 & 98.3 & 32 & 94.1 & 149 & 44.2 & 150 & 44.5 \\
\hline & 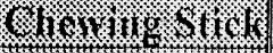 & 23 & 19.3 & 7 & 5.6 & 0 & 0.0 & 2 & 5.9 & 9 & 2.7 & 23 & 6.8 \\
\hline & Bon wivi lioss & 3 & 2.5 & 2 & 1.6 & 1 & 1.7 & 0 & 0.0 & 2 & 0.6 & 4 & 1.2 \\
\hline \multirow{3}{*}{60.} & (m) & 3 & 60.0 & 72 & 75.8 & 1 & 33.3 & 7 & 87.5 & 79 & 71.2 & 4 & 3.6 \\
\hline & 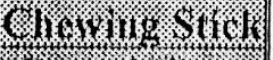 & 2 & 40.0 & 18 & 18.9 & 2 & 66.7 & 1 & 12.5 & 19 & 17.1 & 4 & 3.6 \\
\hline & Buninal 11oss & 0 & 0.0 & 5 & 5.3 & 0 & 0.0 & 0 & 0.0 & 5 & 4.5 & 0 & 0.0 \\
\hline
\end{tabular}

Findings of the study, as shown in table (4), displayed that in the total sample the percentage of subjects without RSC who claimed using cleaning aids $(11.1 \%)$ was higher than those with RSC $(7.3 \%)$. The differences between subjects with and without RSC were statistically significant for all age groups. 
Table (4): A comparison between subjects with and without RSC and the use of clcaning aids according to the age groups

\begin{tabular}{|c|c|c|c|c|c|c|c|c|}
\hline \multirow{2}{*}{ 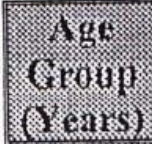 } & \multicolumn{2}{|c|}{ Will inse } & \multicolumn{2}{|c|}{ Wilour ks } & \multicolumn{2}{|c|}{ 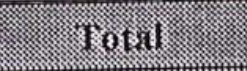 } & \multirow{2}{*}{4.} & \multirow{2}{*}{18} \\
\hline & No. & 8 & Niv. & 4 & No. & . & & \\
\hline $31,=9.9$ & 27 & 7.0 & 53 & 13.7 & 80 & 20.7 & 9.08 & $\mathrm{~S}$ \\
\hline 40.48 & 31 & 7.1 & 57 & 13.1 & 88 & 20.2 & 9.38 & $\mathrm{~S}$ \\
\hline 50.59 & 11 & 3.3 & 27 & 8.0 & 38 & $11: 3$ & 4.37 & $\mathrm{~S}$ \\
\hline 60.60 & 24 & 21.6 & 4 & 3.6 & 28 & 25.2 & 2.4 & $\mathrm{~S}$ \\
\hline Total & 93 & 7.3 & 141 & 11.1 & 334 & 26.3 & 16.87 & $\mathrm{~S}$ \\
\hline
\end{tabular}

$\mathrm{X}^{2}$ between subjects with and without RSC for all age groups:

$\mathrm{X}^{2}=28.508 \quad$ d. $\mathrm{f}=3 \quad \mathrm{~S}=$ Significant

\section{DISCUSSION}

Root surface caries has been and continued to be a major problem for dentate elderly adults. As such, management of root caries in older population is predicted to be one of the greatest challenges facing dental team in the future ${ }^{(16)}$.

Our results support the findings of other study ${ }^{(12)}$, which reported several cases where active root caries was arrested by tooth brushing. Due to frequent tooth brushing, root surface and initial caries lesions on them may become polished enough to arrest a lesion or prevent its initiation. Since most of the toothpastes available in our country have added fluoride, frequent tooth brushing would imply more frequent use of topical fluorides. Several studies have shown that topical fluoride treatment has a preventive effect on root caries $(13,17,18)$. The relationship found in this study between frequency of tooth brushing and root caries may, therefore, reflect the fluoride effect already noted. Since the use of toothpaste is so common, a question was not asked about whether the subjects in this study used toothpastes.

From the findings of this study, the distribution of the study sample according to age and gender, as shown in table (1), which illustrated that the percentage of males in all age groups was higher than that of females except in the age group (30-39) years where the percentage of females was higher $(63.57 \%)$ because usually most of the old women are rarely in the line of jobs with the progressing age.

Results of this study (table 2) revealed that subjects with RSC who never do tooth brushing reported their higher percentage $(8.9 \%)$ in the age group $(50-59)$ years, while those who claimed brushing their teeth infrequently reported their higher percentage $(85.6 \%)$ in the old age group $(60-69)$ years. In contrast, those with RSC who claimed brushing their teeth once a day and twice a day or more reported their higher percentages $(17.3 \%)$ and $(7.8 \%)$, respectively in the yourig age group $(30-39)$ years. The differences between total subjects with and without RSC are statistically significant. These findings are in agreement with the findings of other studies $(11,12,19-$ 21). This may be interpreted by the fact that younger group are with higher degree of awareness concerning dental and oral health education than do older. Also, younger people claimed brushing their teeth more frequently (once a day and twice a day or more) due to the fact that younger people will better take care of their teeth as they brush their teeth more frequently (once a day, twice a day or more).

The findings of this study (table 3) showed that subjects without RSC demonstrated higher percentage of using other cleaning aids (chewing stick and dental 
floss) than those with RSC in all age groups except in the age group $(60-69)$ years, whereas subjects with RSC reported higher percentages of using other cleaning aids than those without $\operatorname{RSC}(17.1 \%$ and $4.5 \%)$, respectively

In addition to that, those subjects whether with or without RSC who never use other cleaning aids reported higher percentages than those who claimed using other cleaning aids. Also, it can be observed from this study (as shown in table 3 ) that the subjects use chewing stick more frequently than the dental floss. All these findings are in agreement with the findings of other studies ${ }^{(16,21-23)}$.

So the differences between subjects with and without RSC are statistically significant for all age groups (as shown in table 4). These findings are in agreement with the findings of other studies ${ }^{(9,22-24)}$. This could be attributed to the fact that the low percentage of subjects who floss their teeth is due to scarce availability of the cleaning aids in the market and lack of its awareness, whereas the majority of the subjects whether with RSC or without, young or old who claimed to use other cleaning aids, claimed to use the chewing stick. This could be explained by the fact that the chewing stick can be a good alternative to the toothbrush since it is inexpensive and readily available. Also, chewing stick contains many medicinal properties, and is available in most rural areas of the poor countries. It does not need expertise or any extra resources to manufacture it. Thus, it is recommended as an important and effective tool for oral hygiene ${ }^{(10)}$. In addition to that the regular use of chewing sticks like the chlorhexidine gluconate may decrease the incidence of periodontal disease and possibly of dental caries as well as these sticks containing vitamin $\mathrm{C}$, fluoride and many ingredients that are important for the dental hard and soft tissues ${ }^{(25)}$

\section{REFERENCES}

1. Wagg BJ. Root surface caries: A review. Community Dent Health. 1984; 1: 11-20.

2. Hardwick JL. The incidence and distribution of caries throughout the ages in relation to the Englishmen's diet. Br Dent J. 1960; 108: 9-17.

3. Lunt DA. The prevalence of dental caries in the permanent dentition of Scottish prehistoric and mediaeval populations. Archs ()ral Biol. 1974; 19: 431-437.

4. Schmschula RG, Keyes PH, Hornabrook FN. Root surface caries in Lufa, New Guinea. I. Clinical observations. I Am Dent Assoc. 1972; 85: 603-608.

5. Schamschula RG, Barmes DE, Keyes PII, Gulbinat W. Prevalence and interrelationship of root surface caries in Lufa, Papua New Guinea. Community Dent Oral Epidemiol. 1974; 2: 295-304.

6. Katz RV. Root caries: Clinical implications of the current epidemiological data. Northwest Dent. 1981; 60: 306-310.

7. Nyvad B, Fejerskov O. Root surfaces caries: Clinical, histopathological and microbiological features and clinical implications. Int Dent J. 1982; 32: 311-326.

8. Fure S, Zickert I. Incidence of tooth loss and dental caries in 60-, 70- and 80years- old Swedish individuals. Commmnity Dent Oral Epidemiol. 1997; 25: 137 142.

9. Fure S. Five - year incidence of caries, salivary and microbial conditions in 60-, 70- and 80-years- old Swedish individuals. Caries Res. 1998; 32: 166-174.

10. Almas K. Miswak (chewing stick) and its role in oral health. Postgrad Dent Middle East. 1993; 3(4): 214-218.

11. Vehkalahti MM, Paunio IK. Occurrence of root caries in relation to dental health behavior. J Dent Res. 1988; 67(6): 911-914. 
12. Nyvad B, Fejerskov O. Active root caries converted to inactive root caries as a response to oral hygienc. Scand J Dent Res. 1986; 94: 281-285.

13. Banting DW, Ellen RP, Fillery ED. $\Lambda$ longitudinal study of root caries: Baseline and incidence data. J Dent Res. 1985; 64: 1141-1144.

14. Axelsson P, Lindhe L. Effect of controlled oral hygiene procedures on caries and periodontal diseases in adults. Results after 6 years. J Clin Periodontol. 1981; 8: 239-248.

15. Banting D, Ellen R, Fillery E. Prevalence of root surface caries among institutionalized older persons. Community Dent Oral Epidemiol. 1980; 8: 84-88.

16. Astroth D. Caring for elderly adult: How to prevent, manage root surface caries? Dent Teamwork. 1996; Sep-Oct: 15-20.

17. Billings $\mathrm{R}$, Brown $\mathrm{L}$, Koster $\mathrm{A}$. Contemporary treatment strategies for root surface dental caries. Gerodontics. 1985; 1: 20-27.

18. Burt $B \wedge$, Ismail $\mathrm{N}$, Lklund $\mathrm{S} \wedge$. Root carties in an optimally fluoridated and a high Cluoride community. J Dent Res. 1986; 65: 1154-1158.

19. Chen MS, Stone DB. Tooth brushing, flossing and dental visits in relation to socioeconomic characteristics of White American females. Community Dent Oral Epidemiol. 1983; 11: 325-332.

20. Athanassouli T, Kolesti-Kounari H, Momai-Homata Ponagopoulos H. Oral health status of adult population in Athens, Greece. Community Dent Oral Epidemiol. 1990; 17: 82-84.

21. Vehkalahti M. Oral hygiene and root caries occurrence in Slovenian adults. Int Dent J. 1997; 47: 26-31.

22. Hahn MJ. The dental status of workers offshore installations in the UK oil and gas industries. Br Dent J. 1987; 163: 262-264.

23. Peterson PE. Evaluation of dental preventive programme for Danish chocolate workers. (community l)ent ()ral lippidemiol. 1989; 17: 53-59,

24. Chen MS, Rubinson L. Preventive dental behavior in families. A national survey. J Am Dent Assoc. 1982; 105: 43-46.

25. Fadulu SO. Antibacterial properties of the buffer extract of chewing stick in Nigeria. Planra Medica. 1975; 27: 123-126. Cited by: Akpata ES, Akinrimisi EO. Antibacterial activity of extract from some African chewing sticks. Oral Surg. 1975; 44: 717-722. 